\title{
Comparative genomic analyses of the cyanobacterium, Lyngbya aestuarii BL J, a powerful hydrogen producer
}

\author{
Ankita Kothari ${ }^{1}$, Michael Vaughn ${ }^{2}$ and Ferran Garcia-Pichel ${ }^{1}$ * \\ 1 School of Life Sciences, Arizona State University, Tempe, AZ, USA \\ ${ }^{2}$ Department of Chemistry and Biochemistry, Arizona State University, Tempe, AZ, USA
}

\section{Edited by: \\ Joseph Kuo-Hsiang Tang, Clark \\ University, USA}

Reviewed by:

Michael Summers, California State

University Northridge, USA

Teresa Thiel, University of

Missouri-St. Louis, USA

Pin-Ching Maness, National

Renewable Energy laboratory, USA

*Correspondence:

Ferran Garcia-Pichel, School of Life Sciences, Life Sciences E-Wing,

Arizona State University, 427 E Tyler

Mall, Tempe, AZ 85287, USA

e-mail:ferran@asu.edu
The filamentous, non-heterocystous cyanobacterium Lyngbya aestuarii is an important contributor to marine intertidal microbial mats system worldwide. The recent isolate $L$. aestuarii $\mathrm{BL} J$, is an unusually powerful hydrogen producer. Here we report a morphological, ultrastructural, and genomic characterization of this strain to set the basis for future systems studies and applications of this organism. The filaments contain circa $17 \mu \mathrm{m}$ wide trichomes, composed of stacked disk-like short cells $(2 \mu \mathrm{m}$ long), encased in a prominent, laminated exopolysaccharide sheath. Cellular division occurs by transversal centripetal growth of cross-walls, where several rounds of division proceed simultaneously. Filament division occurs by cell self-immolation of one or groups of cells (necridial cells) at the breakage point. Short, sheath-less, motile filaments (hormogonia) are also formed. Morphologically and phylogenetically L. aestuarii belongs to a clade of important cyanobacteria that include members of the marine Trichodesmiun and Hydrocoleum genera, as well as terrestrial Microcoleus vaginatus strains, and alkalyphilic strains of Arthrospira. A draft genome of strain $\mathrm{BL} J$ was compared to those of other cyanobacteria in order to ascertain some of its ecological constraints and biotechnological potential. The genome had an average GC content of $41.1 \%$. Of the $6.87 \mathrm{Mb}$ sequenced, $6.44 \mathrm{Mb}$ was present as large contigs (>10,000 bp). It contained 6515 putative protein-encoding genes, of which, $43 \%$ encode proteins of known functional role, $26 \%$ corresponded to proteins with domain or family assignments, $19.6 \%$ encode conserved hypothetical proteins, and $11.3 \%$ encode apparently unique hypothetical proteins. The strain's genome reveals its adaptations to a life of exposure to intense solar radiation and desiccation. It likely employs the storage compounds, glycogen, and cyanophycin but no polyhydroxyalkanoates, and can produce the osmolytes, trehalose, and glycine betaine. According to its genome, BL $J$ strain also has the potential to produce a plethora of products of biotechnological interest such as Curacin A, Barbamide, Hemolysin-type calcium-binding toxin, the suncreens scytonemin, and mycosporines, as well as heptadecane and pentadecane alkanes. With respect to hydrogen production, initial comparisons of the genetic architecture and sequence of relevant genes and loci, and a comparative model of protein structure of the NiFe bidirectional hydrogenase, did not reveal conspicuous differences that could explain its unusual hydrogen producing capacity.

Keywords: biohydrogen, cyanobacteria, bidirectional hydrogenase, hoxH, hydrogen, Lyngbya aestuarii, microbial mats

\section{INTRODUCTION}

Cyanobacteria are deemed ecologically important for their contributions to global nitrogen fixation, and carbon flux (Paul, 1978; Capone et al., 1997) and their global biomass in the order of $10^{14} \mathrm{~g}$ C (Garcia-Pichel et al., 2003) is a relevant component of both terrestrial and marine biomes. Biotechnologically, they possess a great potential to act as cell factories by virtue of their relatively simple structure, minimal nutritional requirements, and an ability to synthesize a wide variety of metabolites. In this study, we focus on the cyanobacterium $L$. aestuarii $\mathrm{BL} J$, a representative

Abbreviations: DDBJ, DNA Database of Japan; EMBL, European Molecular Biology Laboratory. of an ecologically important species in marine intertidal mats, endowed with an extraordinary capacity to produce $\mathrm{H}_{2}$ (Kothari et al., 2012) and thus, of potential biotechnological interest.

In Nature, L. aestuarii forms extensive microbial mats in many marshes and intertidal mud flats (Horodyski and Bloeser, 1977; Mir et al., 1991; Paerl et al., 1991; Lopez-Cortes et al., 2001) Microbial mats are dense laminated benthic communities of micro-organisms (Stal and Caumette, 1993). They present an environment that is extreme in many respects, with repeated cycles of desiccation and wetting, intense exposure to ultraviolet (UV) radiation, and changing regimes of salinity (as cell may be exposed to hypersaline marine waters to very dilute meteoric precipitation). The intertidal mats that are exposed to desiccation are 
restricted in their anaerobic components (Rothrock and GarciaPichel, 2005). Although, as in most microbial communities, $\mathrm{H}_{2}$ is a key metabolite in interspecies metabolic linking, it rarely accumulates to concentrations high enough to be exported in significant amounts. This has been linked to the diverse populations of potential $\mathrm{H}_{2}$ consumers that inhabit these communities (Ebert and Brune, 1997; Schink, 1997). However, certain intertidal microbial mats, where intense net $\mathrm{H}_{2}$ export occurs (Skyring Gw and Smith Gd, 1989; Hoehler et al., 2001), are an exception. In an earlier report we found that, when subjected to the standard $\mathrm{H}_{2}$ production assays in presence of excess reductants, two different patterns were observed. The strains from marine intertidal microbial mats exhibited higher rates, steady state $\mathrm{H}_{2}$ concentrations and a lack of $\mathrm{H}_{2}$ uptake (we called this Pattern $2 \mathrm{H}_{2}$ production), in comparison to those from fresh water, which exhibited lower rates and steady state $\mathrm{H}_{2}$ concentrations followed by uptake of most of the produced $\mathrm{H}_{2}$ (Pattern 1, as was known from standard strain of Synechocytis sp. 6803) (Kothari et al., 2012). The fresh water strain Anabaena sp. PCC 7120 also conformed to Pattern 1 hydrogen production. Thus, the cyanobacteria inhabiting the microbial mats (Pattern $2 \mathrm{H}_{2}$ production) must have evolved extraordinarily powerful hydrogenogenic abilities to produce/sustain hydrogen under the unusually high concentrations of $\mathrm{H}_{2}$ prevailing in their micro-environment. Of the Pattern 2 cyanobacteria, L. aestuarii $\mathrm{BL} J$ had the highest rates and reached the highest steady state $\mathrm{H}_{2}$ concentrations (Kothari et al., 2012). Additionally, this strain also displayed an inducible, strong natural hydrogenogenic capacity under dark fermentative conditions (Kothari et al., in preparation). Infact, the rate of fermentative hydrogen evolution in the strain BL J was 10 times higher than that reported for the closely related strain Oscillatoria limosa (=Lyngbya aestuarii PCC 8106) (Heyer et al., 1989). Hence it was of interest to study the genome of this strain, with a special emphasis on the $\mathrm{H}_{2}$ producing system and the ecophysiological constraints imposed by the environment of origin.

\section{MATERIALS AND METHODS STRAINS AND CULTURE CONDITIONS}

Lyngbya aestuarii strain BL J, a recent isolate from marine intertidal microbial mats in Baja California (Kothari et al., 2012), was grown in IMR medium set at 3\% seawater salinity (Eppley et al., 1968), modified to incorporate a commercially available seawater salt mixture (Instant Ocean), instead of natural seawater, and supplemented with $0.5 \mu \mathrm{M}$ (final concentration) $\mathrm{NiSO}_{4}$. The strain was maintained in axenic form on IMR media $1 \%$ agar plates (since it is less susceptible to contamination than liquid media) at room temperatures and also cryopreserved for long-term storage. Since the strain grew faster in liquid media, it was grown in $250 \mathrm{ml}$ Erlenmeyer flasks, with $100 \mathrm{ml}$ media in presence of $100 \mu \mathrm{mol}$ photon $\mathrm{m}^{2} \mathrm{~s}^{-1}$ light at room temperature to obtain cyanobacterial biomass for microscopy and DNA extractions.

\section{CONFOCAL MICROSCOPY}

A small pellet from liquid culture was washed and resuspended in $300 \mu \mathrm{l}$ of fresh IMR medium. To stain the DNA, 4', 6-diamidino2-phenylindole, DAPI ( $2 \mu \mathrm{g} / \mathrm{ml}$ final concentration) was added. To stain the exopolysaccharide sheath, Fluorescein-labeled lectin (wheat germ agglutinin; $5 \mu \mathrm{g} / \mathrm{ml}$ final concentration) was added. The preparation was incubated for $1 \mathrm{~h}$ in dark at room temperature, and the filaments were washed thrice with fresh IMR medium. Cells were then imaged on glass slides under sealed glass coverslips using a Leica SP5 LASER scanning confocal microscope under a $63 \mathrm{X}$ oil immersion objective. Excitation wavelength for DAPI was at $405 \mathrm{~nm}$, excitation for Fluorescein-labeled lectin was at $488 \mathrm{~nm}$, and photosynthetic pigments were excited at $561 \mathrm{~nm}$. The corresponding emissions were detected at 445-465, 520-535, and $675-715 \mathrm{~nm}$. The images presented were maximum $\mathrm{Z}$ projections with corrected background (to eliminate background noise). All images were acquired at $1024 \times 1024$ pixel resolution. All images were manipulated using the image J software suite (Schneider et al., 2012). Imaging of hormogonia, which showed very fast gliding motility, required the use of carbonyl cyanide $\mathrm{m}$ chlorophenyl hydrazine $(10 \mu \mathrm{m}$ final concentration, for $15 \mathrm{~min}$, Santa Cruz biotech) as an uncoupler of proton motive force, to render them immotile.

\section{TRANSMISSION ELECTRON MICROSCOPY (TEM)}

Unless stated all steps were under room temperature. Samples were primarily fixed in $2.5 \%$ glutaraldehyde in IMR medium for $2 \mathrm{~h}$, followed by four washes in seawater medium over a period of approximately $1 \mathrm{~h}$. Samples were then secondarily fixed with $1 \%$ osmium tetroxide in IMR medium for $2 \mathrm{~h}$. Osmium tetroxide was removed by washing with several changes of deionized water over a period of approximately $1 \mathrm{~h}$, followed by block-staining of the cells with $2 \%$ aqueous uranyl acetate for $1 \mathrm{~h}$. Uranyl acetate was removed by thorough washing in deionized water. Due to poor preliminary results thought to be caused by incomplete dehydration and resin penetration of the cells, the standard TEM preparation procedure was modified to incorporate increased resident-time in dehydrating agent and epoxy resin, as well as additional gradient steps. This involved: $10(\mathrm{v} / \mathrm{v}$ of reagent grade acetone/deionized water), 20, 40,60, 80 , and $100 \%$ anhydrous acetone for four consecutive changes, with each step lasting $30 \mathrm{~m}$. A similar modified approach was employed during infiltration with Spurr's epoxy resin (Spurr, 1969): 10 (v/v of resin/anhydrous acetone), 20,30,50,75\%, and four consecutive changes of pure resin. Each step was under rotation for $12 \mathrm{~h}$ except for the $10 \%$ step, which was $3.5 \mathrm{~h}$. Samples were flat-embedded in fresh resin on Teflon-spray coated glass slides and overlaid with a solid Teflon strip, then polymerized for $24 \mathrm{~h}$ at $60^{\circ} \mathrm{C}$. Small regions of the pellet were selected and excised from the flat resin layer with a razor, then glue-mounted on a blank resin block in the desired orientation for sectioning. Ultra-thin sections $(70 \mathrm{~nm})$ were obtained with a Leica Ultracut-R microtome and collected on formvarcoated $1 \times 2 \mathrm{~mm}$ slotted copper grids. Sections were post-stained for $5 \mathrm{~m}$ with $2 \%$ uranyl acetate in $50 \%$ ethanol solvent followed by $3 \mathrm{~m}$ with Sato's lead citrate (Hanaichi et al., 1986). Images were generated on a Philips CM-12 TEM operated at $80 \mathrm{kV}$ and acquired by a Gatan model 791 slow-scan CCD camera.

\section{DNA EXTRACTION, OUANTIFICATION AND LIBRARY CONSTRUCTION}

Genomic DNA preparations were obtained by PCI (phenol; chloroform; isoamyl alcohol) extraction (Countway et al., 2005). DNA was quantified using fluorometry of ethidium bromide-stained 
$1 \%$ agarose electrophoresis gels and sent for commercial MiSeq 250 Illumina sequencing at the University of Maryland School of Medicine, Institute for Genome Sciences, Genome Resource Center. Genomic DNA libraries were constructed for sequencing on the Illumina platform using the NEBNext ${ }^{\circledR}$ DNA Sample Prep Master Mix Set 1 (New England Biolabs, Ipswich, MA) using the protocol provided, and after DNA fragmentation with an ultrasonicator (Covaris E210). The DNA was purified between enzymatic reactions and the size selection of the library was performed with AMPure XT beads (Beckman Coulter Genomics, Danvers, MA).

\section{DNA SEOUENCING, ASSEMBLY AND ANNOTATION}

Libraries were sequenced using the $250 \mathrm{bp}$ paired-end protocol on an Illumina MiSeq sequencer. Raw data from the sequencer was processed using Illumina's RTA and CASAVA pipeline software, which includes image analysis, base calling, sequence quality scoring, and index demultiplexing. Data was then processed through both in-house pipelines for sequence assessment and quality control and FastQC (http://www.bioinformatics.bbsrc. ac.uk/projects/fastqc/). These pipelines report numerous quality metrics and perform a megablast-based contamination screen. By default, the quality control pipeline assesses basecall quality, and truncates reads where the median Phred-like quality score falls below Q20 (implying more than 99\% accuracy in base calling). Data was randomly sampled to create datasets at 100 , 150, and 200X coverage. The different datasets were assembled with MaSuRCA (Zimin et al., 2013). The genome assembled by MaSuRCA was subjected to the Institute of Genomic Science (Burja et al., 2001) prokaryotic annotation pipeline forms the core of the IGS Annotation Engine. The pipeline includes gene finding, protein searches, and the pFunc evidence hierarchy that produces automated functional annotation. The output of this pipeline was stored in a Chado relational database and accessed by Manatee for annotation visualization and curation (Galens et al., 2011). The genome was also annotated using RAST -Rapid Annotation using Subsystem Technology (Aziz et al., 2008).

\section{GENOMIC ANALYSES}

The genome annotated by Manatee and RAST was also analyzed manually. Homologs of certain key genes of interest were searched as queries of Psi blast of homologs from phylogenetically close protein sequences from NCBI against the entire genome. Given that the genome is not closed, there is a small probability that the genes reported as missing might be present in the unsequenced part of the genome. The Kyoto Encyclopedia of Genes and Genomes (KEGG) was employed by RAST to gain insight into the various metabolic pathway maps.

Since the bidirectional hydrogenase enzyme was central to the powerful $\mathrm{H}_{2}$ production exhibited by the $\mathrm{BL} J$ strain, the architecture of the bidirectional hydrogenase (hox) gene cluster, and hydrogenase accessory genes (hyp) was studied in detail. For the strain BL J, Manatee helped in viewing the genomic organization of the hox and associated ORFs. The physical map of the bidirectional hydrogenase gene cluster and associated ORFs was manually re-constructed to scale in the strains Synechocytis sp. 6803 and Anabaena sp. PCC 7120 (exemplary of Pattern 1),
Microcoleus (=Coleofasciculus) chthnoplastes PCC 7420 and L. aestuarii BL J (exemplary of Pattern 2), Lyngbya aestuarii PCC 8106 and Lyngbya majuscula CCAP 1446/4 (closely related to the strain $\mathrm{BL} \mathrm{J} ; \mathrm{H}_{2}$ production capacity unknown). Protein Psi Blast searches were employed to reveal if any ORFs associated with the hox cluster in BL J were also present in any of the other three strains.

To characterize the phylogenetic placement of this strain in reference to other strains in the same cyanobacterial subsection, $16 \mathrm{~S}$ rRNA sequence (1322 bp) based phylogenetic tree was constructed. The sequences from 83 bacterial species were aligned using ClustalW. The alignment was manually curated and GTR (General Time Reversal model) model with GI (Gamma distributed with Invariant sites) was used to construct maximum likelihood trees with 1000 bootstrap replicates using MEGA 5.2.2 (Tamura et al., 2011).

\section{BIDIRECTIONAL HYDROGENASE SEQUENCE ANALYSIS AND PROTEIN MODELING}

The amino acid sequences of the bidirectional hydrogenase from representatives of Pattern 1 (fresh water strains: Anabaena sp. PCC 7120 and Synechocystis sp. PCC 6803) and Pattern 2 (marine intertidal strains: M. chthonoplastes PCC 7420 and L. aestuarii strain $\mathrm{BL} \mathrm{J}) \mathrm{H}_{2}$ producing cyanobacteria were used for this analysis. The protein sequences of the subunits HoxY and HoxH were individually aligned using Muscle. If the type of amino acid, changed significantly between the two Patterns but remained consistent within a Pattern, it was marked as a significant change (Supplementary Information. 1). The hydrogenase moiety (hoxYH) in Synechocytis sp. 6803 (Pattern 1) and L. aestuarii BL J (Pattern 2) were modeled to study the potential structural importance, of these significant amino acid positions, that might have implications for the function of the bidirectional hydrogenase. Homology models were constructed using the NiFe and NiFeSe hydrogenase templates available in the Protein Data Bank, PDB (Bernstein et al., 1977). Multiple templates were chosen from the PDB for hoxH and hoxY based on the relationship to other bacterial hydrogenases. Both subunits of 1H2A (Higuchi et al., 1997), 1E3D (Matias et al., 2001), 1FRV (Volbeda et al., 1995), 1YQW (Volbeda et al., 2005), and 1CC1 (Garcin et al., 1999) were superimposed using STAMP (Russell and Barton, 1992) and an alignment prepared based on the result using MULTISEQ (Roberts et al., 2006). Each cyanobacterial hydrogenase was profile aligned using CLUSTALW (Larkin et al., 2007) without disturbing the structure-based alignment. The PDB structure files were edited to include protein, the proximal, and medial FeS clusters, the NiFe center, $\mathrm{CO}$, and $\mathrm{CN}$ ligands and the $\mathrm{Fe}$ or $\mathrm{Mg}$ ion at the $\mathrm{C}$-terminus. The previous alignments and edited PDBs were used as inputs for MODELLER (Sali and Blundell, 1993; Eswar et al., 2002) producing 50 independent models. The resulting models were ranked by energy and those with the lowest combined energies were considered in detail. All structures were viewed and figures prepared in Visual Molecular Dynamics software, VMD (Humphrey et al., 1996). The amino acid positions changing consistently between the two patterns were highlighted to study their potential functional significance in the 3D hydrogenase model. 


\section{RESULTS}

\section{STRAIN MORPHOLOGY, UNTRASTRUCTURE, AND DEVELOPMENT}

L. aestuarii $\mathrm{BL} \mathrm{J}$ is a marine filamentous cyanobacterium belonging to the cyanobacterial subsection III according to the classification of Bergey's Manual of Systematic Bacteriology (Boone and Castenholz, 2001). The circa $17 \mu \mathrm{m}$ wide sheathed filaments appeared in various hues of green-brown shades under the light microscope (Figure 1A), as cylindrical, unbranched, and up to $2 \mathrm{~cm}$ in length. The trichome consists of short disk shaped stacked cells (1.6-1.8 $\mu \mathrm{m}$ long). The cells are $14 \mu \mathrm{m}$ wide. Confocal microscopy imaging helped to visualize the DNA and nucleiods (in blue), the exopolysaccharide sheath (in green), and the photosynthetic pigments (in red) (Figures 1E,F). A distinct mucilaginous sheath about $1.6 \mu \mathrm{m}$ in thickness covers the trichome (Figure 1E). As evidenced by confocal microscopy, the main photosynthetic area is arranged parallel to the cross walls, and the nucleoid is central (Figure 1E). This strain often produces short, motile hormogonia as dispersal mechanisms, with little sheath (Figure 1F). The filaments develop necridic cells as a means of filament separation to make new trichomes or to aid in the formation of hormogonia (Figure 1C). Both the vegetative filaments and hormogonia have rounded terminals cells. Sometimes, single disk shaped cells were observed within the sheath and also free in the media (Figure 1D). Cell division was by formation of transversal centripetal growth of cross-walls was

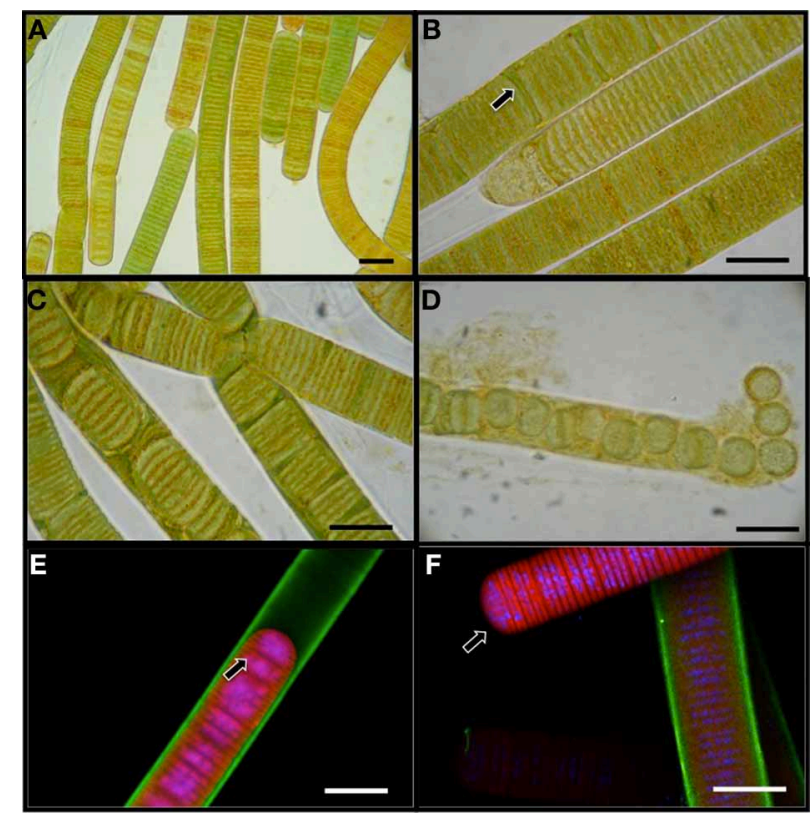

FIGURE 1 | Light microscopy images (A-D) of $\boldsymbol{L}$. aestuarii BL J. (A) The filaments display heterogeneity in pigmentation. (B) Formation of necridial cells (arrow). (C) Short filaments formed by cell division. (D) Breakage of trichome into individual cells or pairs of cells. Fluorescence microscopy images (E,F) depicting the exopolysaccharide sheath stained green, the photosynthetic pigments in red and the nucleic acids stained blue. (E) Cell division by transversal centripetal growth of cross-walls. Arrow marks nascent cell walls. (F) hormogonia (arrow) can be identified by the lack of the exopolysaccharide sheath and motility. A sheathed trichome is in the background. Bar $15 \mu \mathrm{m}$ observed (Figure 1E), often with several consecutive rounds proceeding simultaneously. As expected, heterocysts, akinetes or any other type of specialized cells were absent.

The presence of the thick, laminated exopolysaccharide sheath can be easily visualized in the transversal and longitudinal sections of TEM (appears wider than that observed in fluorescence microscope, perhaps, due to the TEM sample preparation, Figures 2A-D). TEM imaging revealed that the thylakoid membranes were stacked and randomly oriented and present close to the periphery of the cells (Figures 2A,B). The thylakoid membranes were associated with glycogen granules (Figure 2B). Carboxysomes (Figure 2B) and cyanophycin (Figure 2A) granules were observed in the cytoplasm. Formation of new trichomes along with necridial cells was also observed (Figure 2D).

\section{WHOLE GENOME SEOUENCE ANALYSIS Quality of the whole genome sequence}

The draft genome contained 439 contigs of which 124 were large contigs ( $>10,000 \mathrm{bp}$ size). Based on the assembler MaSuRCA, the total contig base pair size was estimated to be $6.87 \mathrm{Mb}$. About $6.44 \mathrm{Mb}$ of the entire genome was present in large contigs. The statistical measure of the median contig size or the N50 value was $80,423 \mathrm{Mb}$. This Whole Genome Shotgun project has been deposited at DDBJ/EMBL/GenBank under the accession AUZM00000000. The version described in this paper is version AUZM01000000.

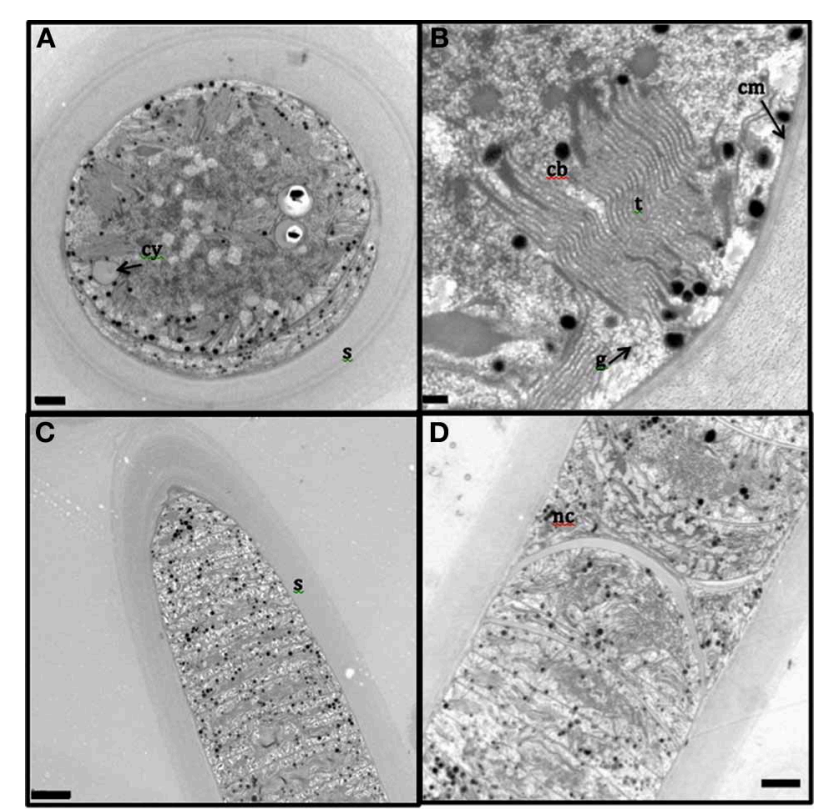

FIGURE 2 | Transmission electron microscopy images of $L$. aestuarii $B L$ J filaments. (A) The transversal section with the stacked thylakoid membranes, randomly oriented, close to the periphery of the cells. The cell contains cyanophycin granules (cy) and thick sheath (s) surrounds the cell; bar $1 \mu \mathrm{m}$. (B) detailed image of the transversal section, displaying the parallel thylakoid membranes (t) along with the polyhedral carboxysomes (cb). A distinct cell membrane (cm) can be observed; bar; $0.2 \mu \mathrm{m}$ (C) Longitudinal section of the filament, displaying the trichome and the thick sheath (s) around it; bar $2 \mu \mathrm{m}$. (D) Longitudinal section displaying necridial cells and newly formed trichomes within the sheath; bar $2 \mu \mathrm{m}$. 


\section{General genomic features}

The chromosome includes 6515 potential protein-encoding genes. $43 \%$ encode proteins with assigned functional role categories, $26 \%$ encode proteins with domain or family assignments, $19.6 \%$ encode conserved hypothetical proteins, which are hypothetical proteins with similarity to other hypothetical proteins and $11.3 \%$ encode hypothetical proteins, with no significant sequence similarity to other proteins. The average size of each gene was $893 \mathrm{bp}$. The tRNA and rRNA were coded by 48 and 5 genes, respectively.

In terms of whole genome DNA sequence similarity, RAST predicts that Arthrospira maxima strain CS-328 and Lyngbya aestuarii PCC 8106 (=strain CCY 9616, formerly referred to as Oscillatoria limosa) are the closest known strains to $L$. aestuarii BL J. Based on 16S rRNA sequence alone, the strain $L$. aestuarii PCC 8106 was the closest (99\% similarity). The GC percentage of the genome L. aestuarii BL J was estimated to be $41.2 \%$. This was closest to the GC percentage of L. aestuarii PCC 8106 $(41.0 \%)$. Certain general features of the genome of sequenced strains closely related to L. aestuarii $\mathrm{BL} J$ have been tabulated (Table 1). In comparison to the closely related strains, the genome size, percent GC, predicted protein encoding genes, and total predicted genes are in the expected range.

\section{Energy metabolism}

As expected, this strain had the homologs of the complete sets of genes coding for both photosystem I, (14 genes; some with additional homologs) and photosystem II, (22 genes; some with additional homologs). It also had homologs of genes coding for phycobilisome proteins, phycocyanin, and allophycocyanin. We

Table 1 | The genome size (denoting the total contig bp sequenced for draft genomes), the percent GC, the number of protein encoding genes and the total number of predicted genes in $L$. aestuarii BL $\mathbf{J}$ and other closely related strains (http://www.ncbi.nlm.nih.gov/).

\begin{tabular}{|c|c|c|c|c|}
\hline Strain & $\begin{array}{l}\text { Genome } \\
\text { size (Mb) }\end{array}$ & $\begin{array}{l}\text { Percent } \\
\text { GC (\%) }\end{array}$ & Protein & Gene \\
\hline L. aestuarii BL J & 6.70 & 41.2 & 6515 & 6568 \\
\hline L. aestuarii PCC 8106 & 7.04 & 41.1 & 6142 & 6185 \\
\hline $\begin{array}{l}\text { Trichodesmium } \\
\text { erythraeum IMS101 }\end{array}$ & 7.75 & 34.1 & 4451 & 5126 \\
\hline $\begin{array}{l}\text { Arthrospira maxima } \\
\text { CS-328 }\end{array}$ & 6.00 & 44.7 & 5690 & 5728 \\
\hline Arthrospira sp. PCC 8005 & 6.17 & 44.6 & 5951 & 6094 \\
\hline $\begin{array}{l}\text { Arthrospira platensis } \\
\text { NIES-39 }\end{array}$ & 6.79 & 44.3 & 6630 & 6676 \\
\hline Arthrospira platensis C1 & 6.09 & 44.8 & 6108 & 6153 \\
\hline $\begin{array}{l}\text { Arthrospira platensis str. } \\
\text { Paraca }\end{array}$ & 5.21 & 44.4 & 4674 & 4718 \\
\hline $\begin{array}{l}\text { Microcoleus vaginatus } \\
\text { FGP-2 }\end{array}$ & 6.70 & 46.0 & - & - \\
\hline $\begin{array}{l}\text { Microcoleus } \\
\text { chthonoplastes PCC } 7420\end{array}$ & 8.68 & 45.4 & 8294 & 8347 \\
\hline Microcoleus sp. PCC 7113 & 7.97 & 46.2 & 6441 & 6821 \\
\hline
\end{tabular}

"-" Data unavailable on the NCB/ website. did not detect homologs of genes coding for phycoerythrocyanin and phycoerythrin. Complete set of genes required for the Calvin cycle (12 genes; some with additional homologs) along with the presence of key enzymes RuBisCo ( $\mathrm{RbcL}$ ), phosphoribulokinase (PRK), and sedoheptulose-1,7-bisphosphatase (SBP) were present, as were the essential genes involved in the Carbondioxide Concentrating Mechanism, or CCM (15 genes; some with additional homologs). The gene hat/hatR (high affinity carbon uptake protein) has 31 homologs in BL J. In strains L. aestuarii PCC 8106, M. chthonoplastes PCC 7420, and Acaryochloris marina, similarly high number of homologs of the same gene can be found, while other strains like Prochlorococcus marinus MIT 9215, Synechococcus sp. WH 8102, Synechococcus sp. CC9311, Cyanothece sp. PCC 8801, and Synechocystis sp. PCC 6803, just contain none to two at most.

Homologs of genes coding photoprotective proteins such as flavodiiron proteins (FPD's) and orange carotenoid proteins were also present. The genome of Synechocystis sp. PCC 6803 contains 4 putative flavodiiron protein-coding genes (CyanoBase: http://bacteria.kazusa.or.jp/cyanobase/) of which two (sllo219 and sll0217) have a role in photoprotection of the cells and in the sustenance of the photosystem II (PSII) complex (Zhang et al., 2009). In comparison, the strain BL J has hosts only 2 putative flavodiiron protein coding genes and with no corresponding homolog to the gene sll0219 in Synechocystis sp. PCC 6803. It has the homologs of genes coding for the photoprotective orange carotenoid protein, also present in closely related strains such as A. maxima CS-328 and L. aestuarii PCC 8106.

With respect to dark carbon catabolic metabolism, it has the homologs of all genes required for glycolysis, Entner-Doudoroff pathway and the pyruvate pentose phosphate pathway. The TCA cycle has homologs of genes similar to that reported in other cyanobacteria, including those (namely 2-oxoglutarate decarboxylase and succinic semialdehyde dehydrogenase) reported to be involved in a cyanobacterial type of TCA cycle (Zhang and Bryant, 2011). The ortholog of the gene coding for succinic semialdehyde dehydrogenase in the strain BL J is reduced (59\% query coverage) compared to that observed in Synechococcus sp. PCC 7002. Similar results were observed in the orthologs of the same gene in closely related strains such as L. aestuarii PCC $8106(68 \%$ query coverage) and Trichodesmium erythraeum IMS101 (64\% query coverage) when compared to the succinic semialdehyde dehydrogenase gene observed in Synechococcus sp. PCC 7002.

This strain has all the genes required for mixed acid fermentation ( 8 genes) for surviving through dark anaerobic conditions [which, in fact, it carries out; (Kothari et al., in preparation)]. Even though a capacity for anoxygenic photosynthesis is typical from microbial mat cyanobacteria (Garcia-Pichel and Castenholz, 1990) we could not detect homologs of the enzyme sulfide:quinone oxidoreductase that catalyses the initial step in sulfide-dependent donation of electrons to PSI.

\section{Nitrogen metabolism}

Cyanobacteria have the ability to use various organic and inorganic sources of nitrogen from the environment. (Luque and Forchhammer, 2008). BL J has all the homologs required for fixing atmospheric nitrogen into ammonium. This includes the 
structural genes nifD and nifK encoding the dinitrogenase moiety and nifH encoding the dinitrogenase reductase. As observed earlier in filamentous strains like Anabaena sp. PCC 7120 (Haselkorn et al., 1998) and L. aestuarii PCC 8106 the genes nifBSUHDKENX are clustered and oriented in a single direction. The homologs of genes coding for the uptake hydrogenase enzyme involved in consumption of the $\mathrm{H}_{2}$ produced by the nitrogenase, are also present in this strain. The genes of coding for the uptake hydrogenase (hupSLW) are generally clustered and oriented in the same direction. In this strain $h u p W$, the putative $\mathrm{C}$ terminal endopeptidase, lies several $\mathrm{kb}$ downstream of the main locus. Interestingly, this strain possesses homologs of the gene het $R$ involved in the formation of heterocysts (Buikema and Haselkorn, 1991), even though it does not develop heterocysts. All genes required for reducing inorganic nitrate into ammonium, including nitrate reductase (nar) and nitrite reductase (Panda et al., 2008), are present. This strain also hosts homologs of genes corresponding to uptake of organic sources of nitrogen (urea) and amino acids (see below), and a homolog of the urease gene.

Ammonium ion assimilation constitutes a central metabolic pathway in cyanobacteria wherein Glutamine synthetase (Burja et al., 2001) and an NADPH-dependent glutamine 2-oxoglutarate amidotransferase (GOGAT) plays the primary role of ammonium ion incorporation into glutamine and glutamate (Muro-Pastor et al., 2005). This strain has the homologs of both Glutamine synthetase and a NADPH-dependent GOGAT. The homolog of the gene coding for $n t c A$ (Vega-Palas et al., 1992) involved in global nitrogen control is also present in this strain.

\section{Signal transduction}

The sensory kinases (involved in sensing the environmental changes) and the response regulators (involved in regulating gene expression) together constitute the "two-component system.” This signal transduction system aids bacteria in adapting to their environmental changes. Only the orthologs of genes coding for the classic two-component systems were detected. This strain has 100 genes coding for the two-component systems (similar values reported in other strains). Of the 100 genes 42 encode histidine kinase A domain protein and the rest code for response regulators.

Additionally, 57 other ORFs were detected with putative role in signal transduction. Of these, about 51 ORFs were assigned as the diguanylate cyclase domain protein-coding gene which participates in the formation of the ubiquitous second messenger cyclic-di-GMP (Ross et al., 1987). The other six ORFs were assigned to the EAL domain protein-coding gene, which is associated with the diguanylate cyclase protein domain. It is a conserved protein domain, proposed to function as diguanylate phosphodiesterase (Galperin et al., 2001).

\section{Transport and binding proteins}

This strain has multiple ORFs with predicted function as binding protein-dependent transport systems. 590 ORFs are predicted to have a role in coding for transport and binding proteins for amino acids, peptides, and amines (9), anions (24), carbohydrates, organic alcohols, and acids (15), cation (56), nucleosides, purines, and pyrimidines (2), Porins (4), other substrates such as heme or polysaccharides (17) and unknown substrate (463). The ORFs involved in anion binding and transfers were homologs of ABC transporter coding genes proposed to transfer phosphate, sulfate, nitrite, phosphonate, phosphite, and molybdate. The ORFs involved in cation binding and transfer were proposed to transport the cations: sodium, copper, ferrous, cadmium, cobalt, magnesium, calcium, potassium, and nickel.

\section{Organic osmotic solutes}

The solute trehalose is characteristic of low-salt tolerant cyanobacteria (Oren et al., 1994), such as Scytonema sp. (PageSharp et al., 1999), Anabaena sp. PCC 7120 (Higo et al., 2006). But it is also present in some marine cyanobacteria such as Crocosphaera watsonii WH8501 (Pade et al., 2012). The genome of this strain had homologs of the enzymes trehalose synthase and trehalose-6-phosphate synthetase involved in trehalose synthesis. However, we did not detect the enzyme trehalase involved in its breakdown. L. aestuarii PCC 8106, seems to use trehalose as a storage compound (Heyer et al., 1989). Glucosylglycerol is an osmolyte commonly seen in moderately halotolerant cyanobacteria Synechocystis PCC 6803 (Hagemann and Erdmann, 1997), Arthrospira (=Spirulina) platensis (Warr et al., 1985), Synechococcus sp. strain 7002 (=Agmenellum quadruplicatum PR6) (Tel-or et al., 1986), Microcystis firma strain Gromow 398 (Erdmann et al., 1992), and Oscillatoria sp. SAG 3192 (Moezelaar et al., 1996). However, we did not detect the genes required for the synthesis of glucosylglycerol in this strain. Glycine betaine is charachteristic of highly halotolerant cyanobacteria Halothece (Aphanothece) halophytica (Reed et al., 1984), Halospirulina tapeticola (Nubel et al., 2000), Spirulina subsalsa (Gabbay-Azaria et al., 1988), Halothece (Dactylococcopsis) salina (Moore et al., 1987), and Synechocystis sp. DUN52 (Mohammad et al., 1983). This solute has also been previously detected in Oscillatoria mats (Oren et al., 1994) inhabiting the hypersaline sulfur hot springs at Hamei Mazor. In cyanobacteria, the enzymes choline dehydrogenase and betaine aldehyde dehydrogenase catalyze the formation of this osmolyte (Oren et al., 1994). Homologs of both of these genes were present in the strain BL J indicating that this strain has the genetic capacity to make glycine betaine.

\section{Storage compounds}

Glycogen is a major carbohydrate reserve molecule in cyanobacteria. Homologs of all the genes involved in glycogen metabolism were detected. Elsewhere we showed that glycogen is stored in the light and mobilized in the dark either aerobically or anaerobically (Kothari et al., in preparation). Cyanophycin (multiL-arginyl-poly-L-aspartate) is a water-insoluble, high nitrogen reserve polymer (Ziegler et al., 1998), quite commonly encountered as a carbon and nitrogen storage polymer in cyanobacteria. (Huang and Chou, 1991; De Philippis et al., 1992; Miller and Espie, 1994). Homologs for the cyanophycin synthetase were also found in BL J. 2 homologs of the cyanophycinase, a peptidase degrading cyanophycin were present, one of which followed the cyanophycin synthetase gene. Polyhydroxyalkanoates or PHAs are linear polyesters storage carbon and energy compounds seen in many cyanobacteria (Stal, 1992; Asada et al., 1999; Hai et al., 
2001; Panda et al., 2008; Shrivastav et al., 2010). However, this strain seems to lack the homologs for poly (3-hydroxyalkanoate) synthase (phaC), the key enzyme for PHA synthesis.

\section{Genes of biotechnological importance}

Secondary metabolites: Polyketide synthases (PKSs) are a family of multi-domain enzymes that produce polyketides, a large class of secondary metabolites. The strain L. aestuarii BL J has genes homologs to the putative polyketide synthase modulerelated protein PKS in Moorea producens 3L (Jones et al., 2011). Homologs of genes involved in Curacin A and Barbamide synthesis (Jones et al., 2011) were also present as were homologs of genes coding for Hemolysin-type calcium-binding toxin seen in L. aestuarii PCC 8106. 3 putative homologs of genes coding for the putative RTX toxin (a type of cytotoxin) along with toxin secretion ABC transporter ATP-binding protein seen in L. aestuarii PCC 8106 were detected as well. Certain cyanobacteria synthesize a protective pigments in response to UV irradiation (Karsten et al., 1998; Gao and Garcia-Pichel, 2011b). Among them, scytonemin, has been directly detected in L. aestuarii mats (Garcia-Pichel and Castenholz, 1991). Previously it has been reported that the scytonemin genes scy $A B C D E F$ are clustered with all the genes oriented in the same direction in a few cyanobacterial strains (Soule et al., 2009). Similar arrangement of scy genes was observed in this strain. Homologs of all the genes essential for the biosynthesis of tryptophan from chorismate $(\operatorname{trp} E, \operatorname{tr} p C$, $\operatorname{trp} A, \operatorname{trp} B, \operatorname{trp} D)$ are present and they are oriented in the direction opposite to that of the scy gene cluster. In fact, the scytonemin gene cluster in the strain BL $\mathrm{J}$ is exactly the same as seen in $L$. aestuarii PCC 8106 (Soule et al., 2009). In response to UV-B irradiation, certain cyanobacteria synthesize mycosporines. This strain has the homologs of all the 3 genes involved in the formation of mycosporine-glycine from sedoheptulose-7-phosphate. All these 3 genes are clustered and oriented in the same direction as reported in Anabaena variabilis ATCC 29413 and Nostoc punctiforme ATCC 29133. There is a homolog of the gene involved in the conversion Mycosporine-glycine to Shinorine, present elsewhere in the genome (Gao and Garcia-Pichel, 2011a).

Certain cyanobacterial strains (Schirmer et al., 2010; Starkenburg et al., 2011) have the genes coding for the synthesis of heptadecane and pentadecane alkanes; a major constituent of gasoline, diesel, and jet fuel. The homologs of genes acyl-[acyl carrier protein] (ACP) reductase and aldehyde decarbonylase involved in the synthesis of heptadecane and pentadecane alkanes (Schirmer et al., 2010) are present in this strain. Homologs of these genes are also present in closely related strains such as L. aestuarii PCC 8106, Microcoleus vaginatus FGP-2, and Trichodesmium erythraeum IMS101.

\section{Other genes of interest}

This strain has genes for resistance to copper, cobalt, zinc, cadmium, mercury, fluoroquinolones, arsenic, and beta-lactam antibiotics. The homolog of the gene involved in biotin synthesis (BioA) could not be detected in this strain. However, it did encode genes for biotin uptake from the environment (and biotin was a constituent of the IMR medium), a trait also seen in other closely related strains. The genome has genes coding for hipBA, which are proposed to have a role in formation of persister cells (dormant cells with antimicrobial resistance) in response to antibiotic and other stresses (Jayaraman, 2008). The genome has genes corresponding to Internalin- putative, Inl, and Internalin A, InlA that are implicated internalization or virulence in Listeria (Cossart and Lecuit, 1998).

\section{COMPARATIVE ANALYSIS OF THE BIDIRECTIONAL HYDROGENASE AND ACCESSORY PROTEINS \\ Bidirectional hydrogenase}

We compared the bidirectional hydrogenase and hydrogenase accessory gene cluster of strains displaying either Pattern 1 (Synechocystis sp. PCC 6803 and Anabaena sp. PCC 7120) or Pattern 2 (L. aestuarii BL J and M. chthonoplastes PCC 7420) $\mathrm{H}_{2}$ production, and included comparisons with closely related Lyngbya species, L. aestuarii PCC 8106, and L. majuscula CCAP 1446/4 (of untested $\mathrm{H}_{2}$ production capacity). L. aestuarii strain BL J hosts a Ni-Fe bidirectional hydrogenase enzyme the locus of which is a $6.89 \mathrm{~kb}$ gene cluster. The genes coding for the bidirectional hydrogenase (hoxEFUYH) are often grouped together as in the strain PCC 7420, but a few other ORFs are interspersed in the cluster of Synechocystis sp. PCC 6803 (Schmitz et al., 1995). In Synechococcus elongatus and in Anabaena sp. PCC 7120 (Boison et al., 1998; Kaneko et al., 2001) the two clusters, hoxEF, and hox$U Y H$ are separated by several $\mathrm{kb}$. The clusters hoxEF and hoxUYH are separated by a single gene coding for $h c p$ (encoding a putative hybrid cluster protein) in Lyngbya strains CCAP 1446/4, PCC 8106 (Ferreira, 2009), and BL J. In fact, the overall arrangement of genes and ORFs in the hydrogenase cluster in L. aestuarii BL J is undistinguishable from that seen in PCC 8106 (Figure 3).

In terms of protein sequence, the bidirectional hydrogenase from $L$. aestuarii PCC 8106 was the closest to that of $L$. aestuarii $\mathrm{BL}$ J. Identities in the hoxE, F, U, Y and $\mathrm{H}$ between the two strains were 97, 97, 97, 96, and 95\%, respectively, and gene lengths for each subunit were the same in both strains. Similar to what was previously reported for L. majuscula CCAP 1446/4 and L. aestuarii PCC 8106 (Ferreira, 2009), the ORF before hoxE is annotated as a pyruvate ferredoxin oxidoreductase in the strain BL J. Pyruvate ferredoxin oxidoreductase is a key enzyme in fermentation, and is typically active in dark anaerobic conditions along with the bidirectional hydrogenase (Kletzin and Adams, 1996). Homologs of the ORF M595_4252 (belonging to BL J strain) are also found in PCC 8106 (L8106_07436) and CCAP 1446/4 (ORF 14) strain. This ORF codes for a hypothetical protein with three predicted transmembrane helices along with homology to cyanobacterial genes coding for putative membrane proteins. Similarly, homologs of other hydrogenase-clusterassociated-ORFs in BL J strain (M595_4253, M595_4255, and M595_4256) were seen in PCC 8106 and CCAP 1446/4 strains (Figure 3).

The gene, hoxW, codes for a carboxyl-terminal protease that releases a 24-amino-acid peptide from HoxH prior to progression of subunit assembly (Thiemermann et al., 1996). HoxW is found immediately downstream of hoxH in S. elongatus PCC 6301, S. elongatus PCC 7942, and Synechococcus sp. PCC 7002. However, hoxH and hoxW are separated by several $\mathrm{kb}$ in Synechocystis sp. PCC 6803 (Kaneko and Tabata, 1997) and M. chthonoplastes PCC 


\section{Pattern 1}

Synechocystis sp. PCC 6803

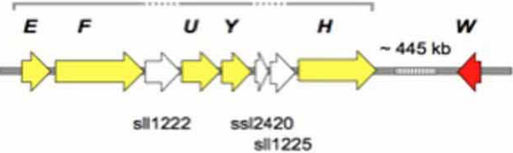

Anabaena variabilis PCC 7120

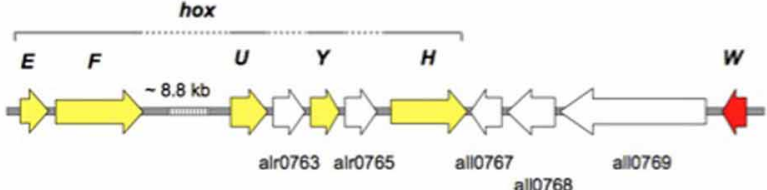

Pattern 2

Microcoleus chthonoplastes PCC 7420

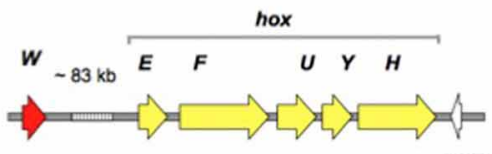

sll1222

Lyngbya aestuarii BL J

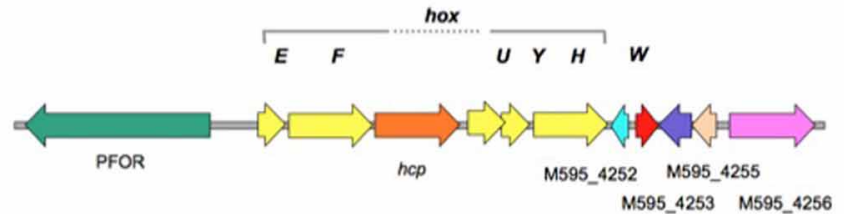

Lyngbya aestuarii PCC 8106

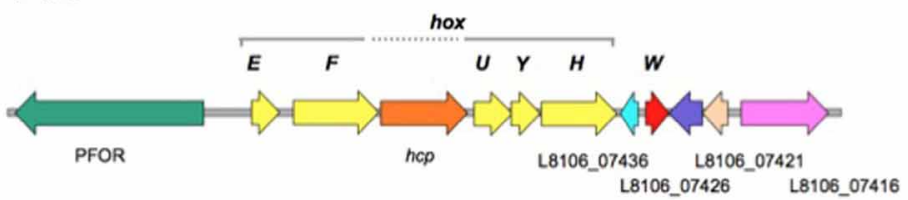

Lyngbya majuscula CCAP 1446/4

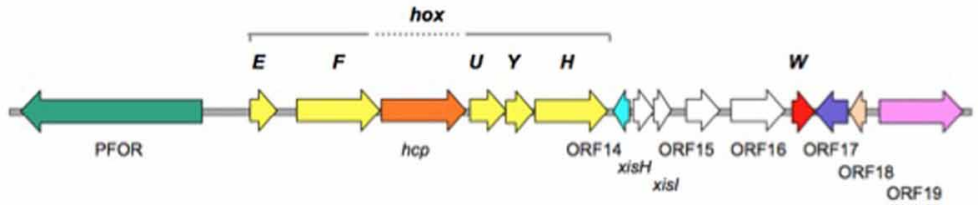

FIGURE 3 | Comparison of the physical map of the bidirectional hydrogenase gene cluster and associated ORFs in Pattern 1 (Synechocytis sp. 6803 and Anabaena PCC 7120) and Pattern 2 (M. chthnoplastes PCC 7420 and $L$. aestuarii BL J) $\mathrm{H}_{2}$ production displaying strains. The genomic regions from other closely related $L y n g b y a$ species $(L$. aestuarii PCC 8106 and L. majuscula CCAP 1446/4) are included for reference (Ferreira, 2009). The following ORFs are depicted: hox genes (yellow ORFs), hoxW (red ORFs), and some additional ORFs (shown as white ORFs, or colored ORFs (including Pyruvate Formate Oxido Reductase, PFOR; Hybrid Cluster Protein, hcp) when homologs to the ones in L. aestuarii BL J).
7420. Three ORFs separate the hoxH and hoxW in Anabaena sp. PCC 7120. A single ORF separates the hoxH gene from hoxW in the L. aestuarii strains (L. majuscula CCAP 1446/4, L. aestuarii PCC 8106, and L. aestuarii BL J).

The genes hypFCDEAB code for the maturation of bidirectional hydrogenase in cyanobacteria (Lutz et al., 1991;
Jacobi et al., 1992). Amongst the Pattern 1 exhibiting strains, the hyp genes are dispersed in the genome of Synechocystis sp. PCC 6803 (Kaneko et al., 1996) whereas they are clustered and oriented in the same direction in Anabaena PCC 7120 with an additional ORF (coding for probable 4-oxalocrotonate tautomerase) between the hypD and hypE genes. In PCC 7420, one 
finds two clusters ( $h y p A B$ and hypFCDE) with additional hypothetical ORFs between $h y p F$ and hypC and another one between hypD and hypE. In the strain BL J, hypFCDEAB are clustered, with all genes oriented in the same direction and encompassing two additional ORFs coding for hypothetical proteins. A similar arrangement has been observed in L. aestuarii PCC 8106. In $\mathrm{BL} \mathrm{J}$, hypC has one additional homolog in the genome, as does $h y p F$, but the latter is highly truncated (13\% query coverage). No additional homologs of hyp genes are found in Lyngbya strains (CCAP 1446/4 and PCC 8106). In Synechocystis PCC 6803 , additional homologs hypA2 and hypB2 were clustered but they don't seem to play a role in maturation of the bidirectional hydrogenase (Hoffmann et al., 2006). Homologs of the gene hypX, with a proposed role in oxygen tolerance of soluble Ni-Fe hydrogenases in Ralstonia eutropha H16 (Bleijlevens et al., 2004), could not be detected in the strain BL J. Thus, at the level of the physical map of the bidirectional hydrogenase and accessory gene cluster we did not observe any congruent changes consistent within a hydrogen production Pattern.

\section{Protein modeling of the bidirectional hydrogenase}

We modeled the 3D structure of the hydrogenase subunit of the bidirectional hydrogenase from $L$. aestuarii $\mathrm{BL}$ J (as an exemplary of Pattern 2) and Synechocystis sp. PCC 6803 (as an exemplary of Pattern 1) based on the genomic sequence. The model was constructed based on five related bacterial NiFe hydrogenases from the Protein Database. In general, the overall fold and length of the large subunit, hoxH, was similar to the heavy chain of the bacterial NiFe hydrogenase model templates. The C-terminus of the $\mathrm{NiFe}$ hydrogenase aids in nickel insertion prior to its cleavage to allow a structural reorganization of the whole molecule, and the consequent assembly of the holoenzyme (Fritsche et al., 1999). It has been suggested that in the cyanobacterial bidirectional hydrogenases, the last 25-32 C-terminal amino acids are cleaved (Tamagnini et al., 2007). The alignments leading to the homology models presented in this work demonstrate strong homology in the $\mathrm{C}$ terminal region and both the strains are consistent with an excised C-terminal portion of 25 amino acids. As reported earlier, the small subunit, hoxY, is significantly shorter in the cyanobacterial bidirectional hydrogenases than in the light chain of the bacterial NiFe hydrogenase model templates. The light chain template structures of NiFe hydrogenases that corresponded to hoxY consisted of 2-folded domains connected through a linear unstructured sequence. Only the first domain of the light chain template is homologs to the cyanobacterial hoxY sequence. The amino acids corresponding to hoxY only house one of the three $\mathrm{FeS}$, which corresponds to the proximal FeS cluster observed in the light chain of the bacterial NiFe hydrogenase model templates.

The 2-fold purpose of the structural comparison was to determine if there were significant structural differences in the enzyme itself and if the consistent amino acids substitutions between representatives of the two hydrogen production Patterns, were located in proximity to active sites in the enzyme. Our results indicate that the overall fold and domain structures between the hydrogenase subunits of L. aestuarii BL J and Synechocystis sp. PCC 6803 were indeed very similar (Figure 4). In comparing protein sequences we found that there were 15 positions in hoxH and 5 in hoxY where the type of amino acid remained consistent within a Pattern but varied amongst the two Patterns (see supplementary information 2). However, all of these significant amino acid changes between the two Patterns lie on the exterior loops in the model (Figure 4) indicating they were not crucial in explaining the differences in the $\mathrm{H}_{2}$ producing physiologies observed between the two Patterns.

\section{DISCUSSION}

Our genomic and cellular description of L. aestuarii BL J shows that this strain shares phylogenetic placement, morphological, and life history traits, with certain other environmentally and biotechnologically relevant cyanobacteria. This clade (Supplementary Information. 2) encompasses globally important marine cyanobacteria like Trichodesmium spp. and globally relevant terrestrial forms such as Microcoleus vaginatus, estimated to be the $3 \mathrm{rd}$ and 4 th most abundant cyanobacteria on the planet, respectively (Garcia-Pichel et al., 2003). The group includes strains in the genus Arthrospira of importance for large scale production of biomass $(\mathrm{Hu}, 2004)$ and used commercially as "Spirulina" as a health food additive (Milledge, 2011) and, of course many other strains of Lyngbya in the so-called Halophilic/brackish/freshwater cluster of biotechnological fame because of their rich and diverse set of secondary metabolites (Engene et al., 2011). All of them being filamentous, nonheterocystous, with discoidal, rather large cells that undergo several rounds of division simultaneously by invagination of cross-walls, and that develop necridial cells for the formation of dispersive hormogonia and for filament separation (Figures 1, 2). Unfortunately given their importance, there are currently no members of this clade for which a system of genetic manipulation has been developed, heavily curtailing biotechnological advancement and bringing and added value to genomic investigations of their members. Given this lack, genomics provides an

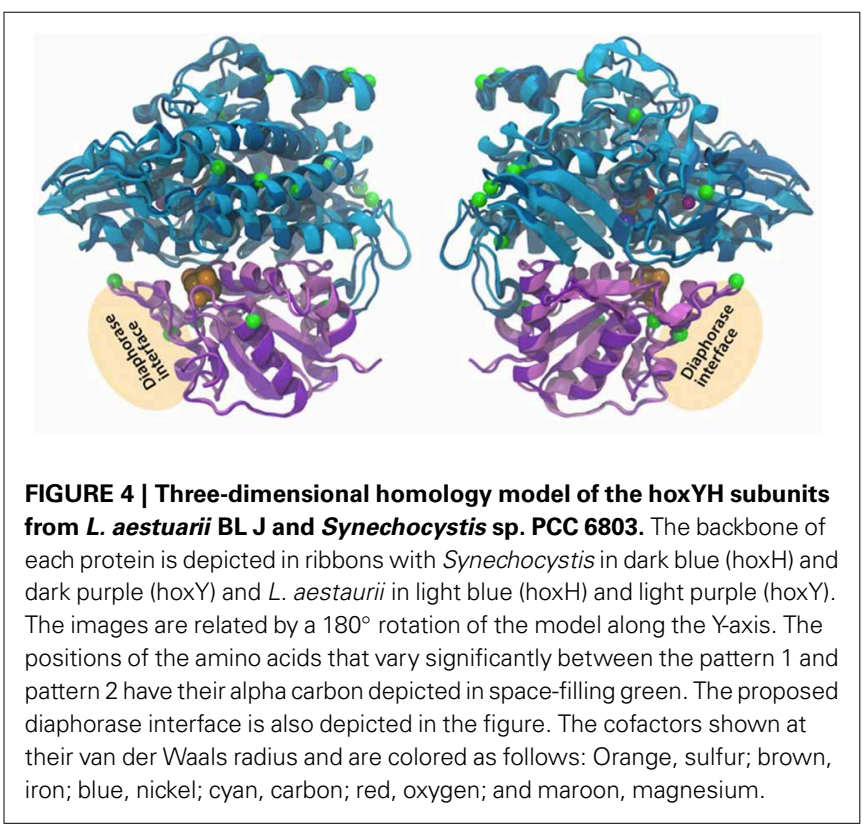


opportunity to identify and transform genes of interest into other model organisms.

The strain L. aestuarii PCC 8106, isolated from a similar intertidal habitat (a microbial mat in the German Wadden Sea island of Mellum), was the closest to BL J both in terms of the $16 \mathrm{~S}$ rRNA sequence similarity and phylogeny, and many of the other genomic features (the genome size, percent GC, predicted protein encoding genes and total predicted genes; Table 1). However, significant differences exist between these two strains. Perhaps the most conspicuous being that BL J is almost 50\% larger than PCC 8106, with reported cell width around $10 \mu \mathrm{m}$ (Stal and Krumbein, 1981). Other features like the arrangement of the thylakoid membranes in stacks does not occur in PCC 8196 either (Stal and Krumbein, 1981). We also report the occasional presence of loose, disk-shaped cells within the sheath and the in the media, indicating that cell-to-cell linkages in our strain can be weak, in what can potentially be relevant as an additional means of dispersal that will require focused study.

Our genomic predictions found confirmation in a variety of traits that could be independently assessed. For example, electron microscopy (Figure 2) confirmed the predicted presence of glycogen as a major carbohydrate storage molecule in this strain to the exclusion of polyhydroxyalkanoates. It did also confirm the genomic predictions of cyanophycin synthesis (Figure 2A) and the formation of carboxysomes. Light microscopy revealed the presence of scytonemin in the sheaths of BL J (and we could confirm its preferential synthesis under added UV-A radiation; data not shown), supporting the finding of the entire scytonemin operon in the genome. This all lends credence to other yet to be supported predictions.

A reading of $L$. aestuarii BL J's genome also speaks directly to some of the environmental constraints of this species in its environment of origin. Known to inhabit exposed intertidal surfaces and the topmost layers of the microbial mats, a high-light phenotype can clearly be surmised from the presence of many photoprotective mechanisms, from extra and intracellular sunscreens, to FPD's that regenerate excess electrons by reducing molecular oxygen to water (Goncalves et al., 2011), to orange carotenoid protein, which helps decouple the light-harvesting systems from the reaction centers (Wilson et al., 2006), as well as from the absence of genes coding for light harvesting pigments that can be considered adaptations to low light intensity like phycoerythrin (Kana and Glibert, 1987), phycoerythrocyanin (Prufert-Bebout and Garcia-Pichel, 1994), or chlorophyll d (Swingley et al., 2008). Intertidal habitats are recurrently exposed to cycles of desiccation and rewetting. Not much is known about the genes involved in desiccation resistance in cyanobacteria but recent transcriptomic studies on the terrestrial strain Microcoleus vaginatus indicate than this is a complex response that involves large sets of genes (Rajeev et al., 2013) and which include complex DNA repair responses, up-regulation of reactive oxygen detoxification mechanisms, the production of osmolites and upregulation of orange carotenoid proteins. Many of the genes involved in these adaptations are also present in this strain, but its mere presence cannot necessarily be linked to desiccation stress resistance. This strain has clearly acquired mechanisms to hold on to moisture, however. In fact, it was very difficult to dehydrate the filaments of this strain for the purpose of TEM preparation. Its thick sheath and the predicted presence of glycine betaine, unusual for a non-halophilic strain, in addition to trehalose, might help in providing desiccation resistance. Finally, a condition typical of the mat habit is that diffusion becomes the major transport mechanism for substrates and products of metabolism. This tends to create diffusion limitations to metabolic activities like photosynthesis and respiration (Garcia-Pichel et al., 1994), which gives relevance to the presence of homologs of genes coding for high affinity carbon uptake protein (hat) and carbon concentrating mechanism $(\mathrm{ccm})$ along with abundant carboxysomes (Figure 2). It also promotes the establishment of anaerobiosis at night within the mat due to consumption by respiration. Under these conditions fermentation of internal reserves though a mixed acid pathway is the only energy-generating metabolism available to strain BL J. Interestingly, this strain lacks the capacity to perform anoxygenic photosynthesis using hydrogen sulfide as an electron donor (homologs of the gene coding for sulfide quinone oxidoreductase were missing) common in microbial mat cyanobacteria. Perhaps this is linked to the low concentrations of sulfide in the upper layers of these intertidal mats compared to mats that are constantly submerged, and where Lyngbya never dominates (Rothrock and Garcia-Pichel, 2005). The presence of recurrent anaerobic conditions will also make soluble ferrous iron available, perhaps leading to the fact that adaptations to iron deficiency such as the products of "iron-stress-induced" gene, isiA; (Straus, 1994; Park et al., 1999) were not detected in $\mathrm{BL}$.

On the biotechnological potential of this strain we have to note its apparently very rich set of secondary metabolites that range from toxins like Curacin A, Barbamide, Hemolysintype calcium-binding toxin, to suncreens like scytonemin and mycosporines, to biofuel prospects like heptadecane and pentadecane alkanes. But clearly, biohydrogen is the most promising product of biotechnological importance from this strain (Kothari et al., 2012). Since the standard assays for hydrogen production were performed in the presence of nitrate, a condition in which nitrogenase is not known to be inactive (Ferreira et al., 2009), we rule out the role of nitrogenase in the production of hydrogen. The uptake hydrogenases are known to produce little hydrogen in presence of reduced methyl viologen (Houchins and Burris, 1981). In contrast, reduced methyl viologen is commonly used to assay the bidirectional hydrogenase activity and is likely the enzyme majorly contributing to the strong hydrogen producing capacity of the strain BL J described previously (Kothari et al., 2012). Therefore, the bidirectional hydrogenase gene cluster in this strain is studied in detail with comparisons drawn to other hydrogen producing strains. The organization of the bidirectional hydrogenase (hox) and accessory hydrogenase (hyp) gene cluster was unique in all the four strains (Synechocystis sp. PCC 6803, Anabaena sp. PCC 7120, L. aestuarii $\mathrm{BL} \mathrm{J}$, and $M$. chthonoplastes PCC 7420). A priori, the comparative analysis of the organization of the bidirectional hydrogenase and accessory genes locus revealed no major changes consistent within a Pattern but varying between the two Patterns. A comparative analysis of the organization of the bidirectional hydrogenase locus in the strain $\mathrm{BL} J$ revealed that it 
was similar to that of L. aestuarii PCC 8106 and showed only minor differences with that of L. majuscula CCAP 1446/4 strain (Figure 3).

Interestingly, in all of the Lyngbya strains (Figure 3), a homolog of the hcp gene, predicted to code for hydroxylamine reductase (Wolfe et al., 2002) and typically associated with detoxification of by-products of nitrate reduction (Cabello et al., 2004), is found between genes hoxF and hoxU. Interestingly, in cyanobacteria that are strong hydrogen producers and display sustained concentrations of hydrogen for more than $24 \mathrm{~h}$ in dark anaerobic conditions (Ananyev et al., 2008; Kothari et al., in preparation), the $h c p$ gene is present, while it is absent from the genomes of Pattern 1 strains, namely, Synechocystis sp. PCC 6803 and Anabaena sp. PCC 7120. This coincidence may provide a hypothesis worth elucidating the high hydrogenogenic capacity of the Pattern 2 strains. Although typically hcp is annotated as hydroxylamine reductases, it also presents significant homology to known carbon monoxide dehydrogenase $(\mathrm{CODH})$. Perhaps the product of hcp plays a role in the generation of CO needed (Pierik et al., 1999) for the maturation of the NiFe hydrogenases. The source of the CO ligand in the $\mathrm{NiFe}$ hydrogenases continues to be unknown (Bürstel et al., 2011).

At the level of hoxYH sequence comparison, we could detect some amino acids substitutions that were consistent within a Pattern but differed amongst the two Patterns. However, none of these amino acids mapped close to the enzyme's active sites, when located on 3D structural models of the hydrogenases of L. aestuarii BL J or Synechocystis PCC 6803 (Figure 4), implying that they are unlikely to modify reaction rates. This suggests that polypeptide differences of the hydrogenase enzyme between the two Patterns are unlikely to explain the functional differences detected previously, necessitating, further study of the biochemistry and regulation of the bidirectional hydrogenase enzymes in these strains. Heterologous expression of the bidirectional hydrogenase from $L$. aestuarii BL J in model strains such as Synechocystis PCC 6803 might help in gaining a better understanding of the enzyme system.

\section{AUTHOR CONTRIBUTIONS}

Concept by Ferran Garcia-Pichel and Ankita Kothari, experimental work (phenotypic and genetic analyses) by Ankita Kothari and 3D hydrogenase enzyme modeling by Michael Vaughn. Writing by Ankita Kothari (with assistance from Michael Vaughn on 3D enzyme modeling) and editorial help by Ferran Garcia-Pichel.

\section{ACKNOWLEDGMENTS}

This research and Ankita Kothari were supported by an endowment from B. Swette through the ASU President's Fusion Fund. The funding source had no involvement in experimental design, data collection, analysis, report writing or decision to submit article. We thank David Lowry and Estelle Couradeau for help with the TEM, Brandon Guida for assistance with the confocal microscopy and Daniela Ferreira for assistance with the scytonemin production assay.

\section{SUPPLEMENTARY MATERIAL}

The Supplementary Material for this article can be found online at: http://www.frontiersin.org/journal/10.3389/fmicb. 2013.00363/abstract

\section{REFERENCES}

Ananyev, G., Carrieri, D., and Dismukes, G. C. (2008). Optimization of metabolic capacity and flux through environmental cues to maximize hydrogen production by the cyanobacterium Arthrospira (Spirulina) maxima. Appl. Environ. Microbiol. 74, 6102-6113. doi: 10.1128/AEM. 01078-08

Asada, Y., Miyake, M., Miyake, J., Kurane, R., and Tokiwa, Y. (1999). Photosynthetic accumulation of poly-(hydroxybutyrate) by cyanobacteria- the metabolism and potential for CO2 recycling. Int. J. Biol. Macromol. 25, 37-42. doi: 10.1016/ S0141-8130(99)00013-6

Aziz, R. K., Bartels, D., Best, A. A., Dejongh, M., Disz, T., Edwards, R. A., et al. (2008). The RAST server: rapid annotations using subsystems technology. BMC Genomics 9, 75. doi: 10.1186/1471-2164-9-75

Bernstein, F. C., Koetzle, T. F., Williams, G. J., Meyer, E. F. Jr., Brice, M. D., Rodgers, J. R., et al. (1977). The protein data bank. A computer-based archival file for macromolecular structures. Eur. J. Biochem. 80, 319-324. doi: 10.1111/j.14321033.1977.tb11885.x

Bleijlevens, B., Buhrke, T., van der Linden, E., Friedrich, B. R., and Albracht, S. P. (2004). The auxiliary protein HypX provides oxygen tolerance to the soluble [NiFe]-hydrogenase of Ralstonia eutropha $\mathrm{H} 16$ by way of a cyanide ligand to nickel. J. Biol. Chem. 279, 46686-46691. doi: 10.1074/jbc.M406942200

Boison, G., Schmitz, O., Schmitz, B., and Bothe, H. (1998). Unusual gene arrangement of the bidirectional hydrogenase and functional analysis of its diaphorase subunit HoxU in respiration of the unicellular cyanobacterium Anacystis nidulans. Curr. Microbiol. 36, 253-258. doi: 10.1007/s002849900305

Boone, D. R., and Castenholz, R. W. (2001). Bergey's Manual of Systematic Bacteriology. New York, NY: Springer-Verlag. doi: 10.1007/978-0-387-21609-6

Buikema, W. J., and Haselkorn, R. (1991). Characterization of a gene controlling heterocyst differentiation in the cyanobacterium Anabaena 7120. Genes Dev. 5, 321-330. doi: 10.1101/gad.5.2.321

Burja, A. M., Banaigs, B., Abou-Mansour, E., Grant Burgess, J., and Wright, P. C. (2001). Marine cyanobacteriaĆ a prolific source of natural products. Tetrahedron 57, 9347-9377. doi: 10.1016/S0040-4020(01)00931-0

Bürstel, I., Hummel, P., Siebert, E., Wisitruangsakul, N., Zebger, I., Friedrich, B. et al. (2011). Probing the origin of the metabolic precursor of the CO ligand in the catalytic center of [NiFe] hydrogenase. J. Biol. Chem. 286, 44937-44944. doi: 10.1074/jbc.M111.309351

Cabello, P., Pino, C., Olmo-Mira, M. F., Castillo, F., Roldan, M. D., and MorenoVivian, C. (2004). Hydroxylamine assimilation by Rhodobacter capsulatus E1F1. Requirement of the hcp gene (hybrid cluster protein) located in the nitrate assimilation nas gene region for hydroxylamine reduction. J. Biol. Chem. 279, 45485-45494. doi: 10.1074/jbc.M404417200

Capone, D. G., Zehr, J. P., Paerl, H. W., Bergman, B., and Carpenter, E. J. (1997) Trichodesmium, a globally significant marine cyanobacterium. Science 276, 1221-1229. doi: 10.1126/science.276.5316.1221

Cossart, P., and Lecuit, M. (1998). Interactions of Listeria monocytogenes with mammalian cells during entry and actin-based movement: bacterial factors, cellular ligands and signaling. EMBO J. 17, 3797-3806. doi: 10.1093/emboj/17. 14.3797

Countway, P. D., Gast, R. J., Savai, P., and Caron, D. A. (2005). Protistan diversity estimates based on $18 \mathrm{~S}$ rDNA from seawater incubations in the western North Atlantic. J. Eukaryot. Microbiol. 52, 95-106. doi: 10.1111/j.15507408.2005.05202006.x

De Philippis, R., Claudio, S., and Massimo, V. (1992). Glycogen and polyalpha-hydroxybutyrate synthesis in Spirulina maxima. J. Gen. Microbiol. 138, 1623-1628. doi: 10.1099/00221287-138-8-1623

Ebert, A., and Brune, A. (1997). Hydrogen concentration profiles at the oxic-anoxic interface: a microsensor study of the hindgut of the wood-feeding lower termite reticulitermes flavipes (Kollar). Appl. Environ. Microbiol. 63, 4039-4046.

Engene, N., Choi, H., Esquenazi, E., Rottacker, E. C., Ellisman, M. H., Dorrestein, P. C., et al. (2011). Underestimated biodiversity as a major explanation for the perceived rich secondary metabolite capacity of the cyanobacterial genus Lyngbya. Environ. Microbiol. 13, 1601-1610. doi: 10.1111/j.1462-2920.2011.02472.x 
Eppley, R. W., Holmes, R. W., and Strickland, J. D. H. (1968). Sinking rates of marine phytoplankton measured with a fluorometer. J. Exp. Mar. Biol. Ecol.1, 191-208. doi: 10.1016/0022-0981(67)90014-7

Erdmann, N., Fulda, S., and Hagemann, M. (1992). Glucosylglycerol accumulation during salt acclimation of two unicellular cyanobacteria. J. Gen. Microbiol. 138, 363-368. doi: 10.1099/00221287-138-2-363

Eswar, N., Webb, B., Marti-Renom, M. A., Madhusudhan, M. S., Eramian, D., Shen, M.-Y., et al. (2002). Comparative protein structure modeling using Modeller. Curr. Protoc. Bioinformatics 5:6. doi 10.1002/0471250953.bi0506s15

Ferreira, D. (2009). Nitrogen fixation and transcription/regulation of genes related to hydrogenases in Lyngbya spp. Ph.D. thesis, Universidade do Porto, 85-87.

Ferreira, D., Stal, L. J., Moradas-Ferreira, P., Mendes, M. V., and Tamagnini, P. (2009). The relation between $\mathrm{N} 2$ fixation and $\mathrm{H} 2$ metabolism in the marine filamentous nonheterocystous cyanobacterium Lyngbya aestuarii CCY 9616. J. Phycol. 45, 898-905. doi: 10.1111/j.1529-8817.2009.00714.x

Fritsche, E., Paschos, A., Beisel, H. G., Böck, A., and Huber, R. (1999). Crystal structure of the hydrogenase maturating endopeptidase HYBD from Escherichia coli. J. Mol. Biol. 288, 989-998. doi: 10.1006/jmbi.1999.2719

Gabbay-Azaria, R., Tel-Or, E., and Schonfeld, M. (1988). Glycinebetaine as an osmoregulant and compatible solute in the marine cyanobacterium Spirulina subsalsa. Arch. Biochem. Biophys. 264, 333-339. doi: 10.1016/00039861(88)90601-7

Galens, K., Orvis, J., Daugherty, S., Creasy, H. H., Angiuoli, S., White, O., et al. (2011). The IGS standard operating procedure for automated prokaryotic annotation. Stand. Genomic Sci. 4, 244. doi: 10.4056/sigs. 1223234

Galperin, M. Y., Nikolskaya, A. N., and Koonin, E. V. (2001). Novel domains of the prokaryotic two component signal transduction systems. FEMS Microbiol. Lett. 203, 11-21. doi: 10.1111/j.1574-6968.2001.tb10814.x

Gao, Q., and Garcia-Pichel, F. (2011a). An ATP-Grasp ligase involved in the last biosynthetic step of the iminomycosporine shinorine in Nostoc punctiforme ATCC 29133. J. Bacteriol. 193, 5923-5928. doi: 10.1128/JB.05730-11

Gao, Q., and Garcia-Pichel, F. (2011b). Microbial ultraviolet sunscreens. Nat. Rev. Microbiol. 9, 791-802. doi: 10.1038/nrmicro2649

Garcia-Pichel, F., Belnap, J., Neuer, S., and Schanz, F. (2003). Estimates of global cyanobacterial biomass and its distribution. Algol. Stud. 109, 213-227. doi: 10.1127/1864-1318/2003/0109-0213

Garcia-Pichel, F., and Castenholz, R. (1990). Comparative anoxygenic photosynthetic capacity in 7 strains of a thermophilic cyanobacterium. Arch. Microbiol. 153, 344-351. doi: 10.1007/BF00249003

Garcia-Pichel, F., and Castenholz, R. W. (1991). Charachterization and biological implications of scytonemon, a cyanobacterial sheath pigment. J. Phycol. 27, 395-409. doi: 10.1111/j.0022-3646.1991.00395.x

Garcia-Pichel, F., Mechling, M., and Castenholz, R. W. (1994). Diel migrations of microorganisms within a benthic, hypersaline mat community. Appl. Environ. Microbiol. 60, 1500-1511.

Garcin, E., Vernede, X., Hatchikian, E. C., Volbeda, A., Frey, M., and FontecillaCamps, J. C. (1999). The crystal structure of a reduced [NiFeSe] hydrogenase provides an image of the activated catalytic center. Structure 7, 557-566. doi: 10.1016/S0969-2126(99)80072-0

Goncalves, V. L., Vicente, J. B., Saraiva, L. M., and Teixeira, M. (2011). "Flavodiiron proteins and their role in cyanobacteria," in Bioenergetic Processes of Cyanobacteria, eds G. A. Peschek, O. Christian, and R. Gernot (New York, NY: Springer), 631-653.

Hagemann, M., and Erdmann, N. (1997). Environmental Stresses. Cyanobacterial Nitrogen Metabolism and Environmental Biotechnology. Heidelberg: SpringerVerlag, 156-221.

Hai, T., Hein, S., and Steinbochel, A. (2001). Multiple evidence for widespread and general occurrence of type-III PHA synthases in cyanobacteria and molecular characterization of the PHA synthases from two thermophilic cyanobacteria: Chlorogloeopsis fritschii PCC 6912 and Synechococcus sp. strain MA19. Microbiology 147, 3047-3060.

Hanaichi, T., Sato, T., Iwamoto, T., Malavasi-Yamashiro, J., Hoshino, M., and Mizuno, N. (1986). A stable lead by modification of Sato's method. J. Electron Microsc. 35, 304-306.

Haselkorn, R., Schlictman, D., Jones, K., and Buikema, W. (1998). Heterocyst differentiation and nitrogen fixation in cyanobacteria. Curr. Plant Sci. Biotechnol. Agric. 31, 93-96.

Heyer, H., Stal, L., and Krumbein, W. E. (1989). Simultaneous heterolactic and acetate Fermentation in the marine cyanobacterium Oscillatoria limosa incubated anaerobically in the dark. Arch. Microbiol. 151, 558-564. doi: 10.1007/ BF00454875

Higo, A., Katoh, H., Ohmori, K., Ikeuchi, M., and Ohmori, M. (2006). The role of a gene cluster for trehalose metabolism in dehydration tolerance of the filamentous cyanobacterium Anabaena sp. PCC 7120. Microbiology 152, 979-987. doi: 10.1099/mic.0.28583-0

Higuchi, Y., Yagi, T., and Yasuoka, N. (1997). Unusual ligand structure in Ni$\mathrm{Fe}$ active center and an additional $\mathrm{Mg}$ site in hydrogenase revealed by high resolution X-ray structure analysis. Structure 5, 1671-1680. doi: 10.1016/S09692126(97)00313-4

Hoehler, T. M., Bebout, B. M., and Des Marais, D. J. (2001). The role of microbial mats in the production of reduced gases on the early Earth. Nature 412, 324-327. doi: 10.1038/35085554

Hoffmann, D., Gutekunst, K., Klissenbauer, M., Schulz-Friedrich, R., and Appel, J. (2006). Mutagenesis of hydrogenase accessory genes of Synechocystis sp. PCC 6803. Additional homologues of hypA and hypB are not active in hydrogenase maturation. FEBS J. 273, 4516-4527. doi: 10.1111/j.1742-4658.2006. 05460.x

Horodyski, R. J., and Bloeser, B. (1977). Laminated algal mats from a coastal lagoon, Laguna Mormona, Baja California, Mexico. J. Sediment. Res. 47, 680-696.

Houchins, J. P., and Burris, R. H. (1981). Comparative characterization of two distinct hydrogenases from Anabaena sp. strain 7120. J. Bacteriol. 146, 215-221.

$\mathrm{Hu}$, Q. (2004). "12 Industrial production of microalgal cell-mass and secondary products-major industrial species," in Handbook of Microalgal Culture: Biotechnology and Applied Phycology, ed A. Richmond (Pondicherry: Blackwell Publishing) 264-272.

Huang, T.-C., and Chou, W.-M. (1991). Setting of the circadian N2-fixing rhythm of the prokaryotic Synechococcus sp. RF-1 while its nif gene is repressed. Plant Physiol. 96, 324-326. doi: 10.1104/pp.96.1.324

Humphrey, W., Dalke, A., and Schulten, K. (1996). VMD: visual molecular dynamics. J. Mol. Graph. 14, 33-38, 27-38. doi: 10.1016/0263-7855(96) 00018-5

Jacobi, A., Rossmann, R., and Bock, A. (1992). The hyp operon gene-products are required for the maturation of catalytically active hydrogenase isoenzymes in Escherichia coli. Arch. Microbiol. 158, 444-451. doi: 10.1007/BF00 276307

Jayaraman, R. (2008). Bacterial persistence: some new insights into an old phenomenon. J. Biosci. 33, 795-805. doi: 10.1007/s12038-008-0099-3

Jones, A. C., Monroe, E. A., Podell, S., Hess, W. R., Klages, S., Esquenazi, E., et al. (2011). Genomic insights into the physiology and ecology of the marine filamentous cyanobacterium Lyngbya majuscula. Proc. Natl. Acad. Sci. U.S.A. 108, 8815-8820. doi: 10.1073/pnas.1101137108

Kana, T. M., and Glibert, P. M. (1987). "Effect of irradiances up to $2000 \mathrm{Mu}$ E M-2 S-1 on marine synechococcus Wh7803.2. photosynthetic responses and mechanisms," in Deep-Sea Research Part a-Oceanographic Research Papers. (Cambridge, MD), 34, 497-516. doi: 10.1016/0198-0149(87)90002-1

Kaneko, T., Nakamura, Y., Wolk, C. P., Kuritz, T., Sasamoto, S., Watanabe, A., et al. (2001). Complete genomic sequence of the filamentous nitrogen-fixing cyanobacterium Anabaena sp. strain PCC 7120. DNA Res. 8, 205-213. doi: 10.1093/dnares/8.5.205

Kaneko, T., Sato, S., Kotani, H., Tanaka, A., Asamizu, E., Nakamura, Y., et al. (1996). Sequence analysis of the genome of the unicellular cyanobacterium Synechocystis sp. strain PCC 6803. II. Sequence determination of the entire genome and assignment of potential protein-coding regions. DNA Res. 3, 109-136. doi: 10.1093/dnares/3.3.109

Kaneko, T., and Tabata, S. (1997). Complete genome structure of the unicellular cyanobacterium Synechocystis sp. PCC6803. Plant Cell Physiol. 38, 1171-1176. doi: 10.1093/oxfordjournals.pcp.a029103

Karsten, U., Maier, J., and Garcia-Pichel, F. (1998). Seasonality in UV-absorbing compounds of cyanobacterial mat communities from an intertidal mangrove flat. Aquat. Microb. Ecol. 16, 37-44. doi: 10.3354/ame016037

Kletzin, A., and Adams, M. (1996). Molecular and phylogenetic characterization of pyruvate and 2-ketoisovalerate ferredoxin oxidoreductases from Pyrococcus furiosus and pyruvate ferredoxin oxidoreductase from Thermotoga maritima. J. Bacteriol. 178, 248-257.

Kothari, A., Potrafka, R., and Garcia-Pichel, F. (2012). Diversity in hydrogen evolution from bidirectional hydrogenases in cyanobacteria from terrestrial, freshwater and marine intertidal environments. J. Biotechnol. 162, 105-114. doi: 10.1016/j.jbiotec.2012.04.017 
Larkin, M. A., Blackshields, G., Brown, N. P., Chenna, R., Mcgettigan, P. A., Mcwilliam, H., et al. (2007). Clustal W and clustal X version 2.0. Bioinformatics 23, 2947-2948. doi: 10.1093/bioinformatics/btm404

Lopez-Cortes, A., Garcia-Pichel, F., Nubel, U., and Vazquez-Juarez, R. (2001). Cyanobacterial diversity in extreme environments in Baja California, Mexico: a polyphasic study. Int. Microbiol. 4, 249. doi: 10.1007/s10123-001-0044-x

Luque, I., and Forchhammer, K. (2008). "Nitrogen assimilation and C/N balance sensing," in Cyanobacteria: Molecular Biology, Genomics and Evolution, eds A. Herrero, and E. Flores (Sevilla: Caister Academic Press), 335-382.

Lutz, S., Jacobi, A., Schlensog, V., Bohm, R., Sawers, G., and Bock, A. (1991). Molecular characterization of an operon (hyp) necessary for the activity of the 3 hydrogenase isoenzymes in Escherichia coli. Mol. Microbiol. 5, 123-135. doi: 10.1111/j.1365-2958.1991.tb01833.x

Matias, P. M., Soares, C. M., Saraiva, L. M., Coelho, R., Morais, J., Le Gall, J., et al. (2001). [NiFe] hydrogenase from Desulfovibrio desulfuricans ATCC 27774: gene sequencing, three-dimensional structure determination and refinement at 1.8 A and modelling studies of its interaction with the tetrahaem cytochrome $\mathrm{c} 3$. J. Biol. Inorg. Chem. 6, 63-81. doi: 10.1007/s007750000167

Milledge, J. (2011). Commercial application of microalgae other than as biofuels: a brief review. Rev. Environ. Sci. Biotechnol.10, 31-41. doi: 10.1007/s11157-0109214-7

Miller, A. G., and Espie, G. S. (1994). Photosynthetic metabolism of cyanate by the cyanobacterium Synechococcus UTEX 625. Arch. Microbiol. 162, 151-157. doi: 10.1007/BF00314468

Mir, J., Martinez-Alonso, M., Esteve, I., and Guerrero, R. (1991). Vertical stratification and microbial assemblage of a microbial mat in the Ebro Delta (Spain). FEMS Microbiol. Lett. 86, 59-68. doi: 10.1111/j.1574-6968.1991.tb04795.x

Moezelaar, R., Bijvank, S. M., and Stal, L. J. (1996). Fermentation and sulfur reduction in the mat-building cyanobacterium Microcoleus chthonoplastes. Appl. Environ. Microbiol. 62, 1752-1758.

Mohammad, F., Reed, R., and Stewart, W. (1983). The halophilic cyanobacterium Synechocystis DUN52 and its osmotic responses. FEMS Microbiol. Lett. 16, 287-290. doi: 10.1111/j.1574-6968.1983.tb00304.x

Moore, D., Reed, R., and Stewart, W. (1987). A glycine betaine transport system in Aphanothece halophytica and other glycine betaine-synthesising cyanobacteria. Arch. Microbiol. 147, 399-405. doi: 10.1007/BF00406140

Muro-Pastor, M. I., Reyes, J. C., and Florencio, F. J. (2005). Ammonium assimilation in cyanobacteria. Photosynth. Res. 83, 135-150. doi: 10.1007/s11120-0042082-7

Nubel, U., Garcia-Pichel, F., and Muyzer, G. (2000). The halotolerance and phylogeny of cyanobacteria with tightly coiled trichomes (Spirulina Turpin) and the description of Halospirulina tapeticola gen. nov, sp. nov. Int. J. Syst. Evol. Microbiol. 50, 1265-1277. doi: 10.1099/00207713-50-3-1265

Oren, A., Fischel, U., Aizenshtat, Z., Krein, E. B., and Reed, R. H. (1994). "Osmotic adaptation of microbial communities in hypersaline microbial mats," in Microbial Mats, eds L. J. Stal and P. Caumette (Berlin, Heidelberg: Springer), 125-130.

Pade, N., Compaore, J., Klahn, S., Stal, L. J., and Hagemann, M. (2012). The marine cyanobacterium Crocosphaera watsonii WH8501 synthesizes the compatible solute trehalose by a laterally acquired OtsAB fusion protein. Environ. Microbiol. 14, 1261-1271. doi: 10.1111/j.1462-2920.2012.02709.x

Paerl, H. W., Prufert, L. E., and Ambrose, W. W. (1991). Contemporaneous nitrogen fixation and oxygenic photosyntheis in the non heterocystous mat-forming cyanobacterium Lyngbya aestuarii. Appl. Environ. Microbiol. 57, 3086-3092.

Page-Sharp, M., Behm, C. A., and Smith, G. D. (1999). Involvement of the compatible solutes trehalose and sucrose in the response to salt stress of a cyanobacterial Scytonema species isolated from desert soils. Biochim. Biophys. Acta 1472, 519-528. doi: 10.1016/S0304-4165(99)00155-5

Panda, B., Sharma, L., Singh, A. K., and Mallick, N. (2008). Thin layer chromatographic detection of poly-hydroxybutyrate (PHB) and poly-hydroxyvalerate (PHV) in cyanobacteria. Indian J. Biotechnol. 7, 230-234.

Park, Y. I., Sandström, S., Gustafsson, P., and Öquist, G. (1999). Expression of the isiA gene is essential for the survival of the cyanobacterium Synechococcus sp. PCC 7942 by protecting photosystem II from excess light under iron limitation. Mol. Microbiol. 32, 123-129. doi: 10.1046/j.1365-2958.1999.01332.x

Paul, E. A. (1978). Contribution of nitrogen fixation to ecosystem functioning and nitrogen fluxes on a global basis. Ecol. Bull. 26, 282-293.

Pierik, A. J., Roseboom, W., Happe, R. P., Bagley, K. A., and Albracht, S. P. (1999). Carbon monoxide and cyanide as intrinsic ligands to iron in the active site of [NiFe]-hydrogenases. NiFe(CN)2CO, Biology's way to activate H2. J. Biol. Chem. 274, 3331-3337. doi: 10.1074/jbc.274.6.3331

Prufert-Bebout, L., and Garcia-Pichel, F. (1994). "Field and cultivated microcoleus chthonoplastes: the search for clues to its prevalence in marine microbial mats," in Microbial Mats, eds L. J. Stal and P. Caumette (Berlin: Springer), 111-116.

Rajeev, L., Da Rocha, U. N., Klitgord, N., Luning, E. G., Fortney, J., Axen, S. D., et al. (2013). Dynamic cyanobacterial response to hydration and dehydration in a desert biological soil crust. ISME J. 7, 2178-2191. doi: 10.1038/ismej.2013.83

Reed, R. H., Chudek, J. A., Foster, R., and Stewart, W. D. P. (1984). Osmotic adjustment in cyanobacteria from hypersaline environments. Arch. Microbiol. 138, 333-337. doi: 10.1007/BF00410900

Roberts, E., Eargle, J., Wright, D., and Luthey-Schulten, Z. (2006). MultiSeq: unifying sequence and structure data for evolutionary analysis. BMC Bioinformatics 7:382. doi: 10.1186/1471-2105-7-382

Ross, P., Weinhouse, H., Aloni, Y., Michaeli, D., Weinberger-Ohana, P., Mayer, R., et al. (1987). Regulation of cellulose synthesis in Acetobacter xylinum by cyclic diguanylic acid. Nature 325, 279-281. doi: 10.1038/325279a0

Rothrock, M. J., and Garcia-Pichel, F. (2005). Microbial diversity of benthic mats along a tidal desiccation gradient. Environ. Microbiol. 7, 593-601. doi: 10.1111/ j.1462-2920.2005.00728.x

Russell, R. B., and Barton, G. J. (1992). Multiple protein sequence alignment from tertiary structure comparison: assignment of global and residue confidence levels. Proteins 14, 309-323. doi: 10.1002/prot.340140216

Sali, A., and Blundell, T. L. (1993). Comparative protein modelling by satisfaction of spatial restraints. J. Mol. Biol. 234, 779-815. doi: 10.1006/jmbi.1993.1626

Schink, B. (1997). Energetics of syntrophic cooperation in methanogenic degradation. Microbiol. Mol. Biol. Rev. 61, 262-280.

Schirmer, A., Rude, M. A., Li, X., Popova, E., and Del Cardayre, S. B. (2010). Microbial biosynthesis of alkanes. Science 329, 559-562. doi: 10.1126/science.1187936

Schmitz, O., Boison, G., Hilscher, R., Hundeshagen, B., Zimmer, W., Lottspeich, F., et al. (1995). Molecular biological analysis of a bidirectional hydrogenase from cyanobacteria. Eur. J. Biochem. 233, 266-276. doi: 10.1111/j.14321033.1995.266_1.x

Schneider, C. A., Rasband, W. S., and Eliceiri, K. W. (2012). NIH Image to ImageJ: 25 years of image analysis. Nat. Methods 9, 671-675. doi: 10.1038/nmeth.2089

Shrivastav, A., Mishra, S. K., and Mishra, S. (2010). Polyhydroxyalkanoate (PHA) synthesis by Spirulina subsalsa from Gujarat coast of India. Int. J. Biol. Macromol. 46, 255-260. doi: 10.1016/j.ijbiomac.2010.01.001

Skyring Gw, L. R., and Smith Gd, (1989). "Quantitative relationships between carbon, hydrogen, sulfur metabolism in cyanobacterial mats," in Microbial Mats, eds Y. Chen, and E. Rosenberg (Washington, DC: American society of microbiology), 170-179.

Soule, T., Palmer, K., Gao, Q., Potrafka, R. M., Stout, V., and Garcia-Pichel, F. (2009). A comparative genomics approach to understanding the biosynthesis of the sunscreen scytonemin in cyanobacteria. BMC Genomics 10, 336. doi: 10.1186/1471-2164-10-336

Spurr, A. R. (1969). A low-viscosity epoxy resin embedding medium for electron microscopy. J. Ultrastruct. Res. 26, 31-43. doi: 10.1016/S0022-5320(69)90033-1

Stal, L. J. (1992). Poly (hydroxyalkanoate) in cyanobacteria: an overview. FEMS Microbiol. Lett. 103, 169-180. doi: 10.1111/j.1574-6968.1992.tb05835.x

Stal, L.J., and Caumette, P. (1993). Microbial Mats. Berlin, Heidelberg: Springer.

Stal, L. J., and Krumbein, W. E. (1981). Aerobic nitrogen fixation in pure cultures of a benthic marine Oscillatoria (cyanobacteria). FEMS Microbiol. Lett. 11, 295-298. doi: 10.1111/j.1574-6968.1981.tb06983.x

Starkenburg, S. R., Reitenga, K. G., Freitas, T., Johnson, S., Chain, P. S. G., Garcia-Pichel, F., et al. (2011). Genome of the cyanobacterium microcoleus vaginatus FGP-2, a photosynthetic ecosystem engineer of arid land soil biocrusts worldwide. J. Bacteriol. 193, 4569-4570. doi: 10.1128/JB.05138-11

Straus, N. A. (1994). "Iron deprivation: physiology and gene regulation," in The Molecular Biology of Cyanobacteria, ed D. A. Bryant (Dordrecht: Springer), 731-750. doi: 10.1007/978-94-011-0227-8_25

Swingley, W. D., Chen, M., Cheung, P. C., Conrad, A. L., Dejesa, L. C., Hao, J., et al. (2008). Niche adaptation and genome expansion in the chlorophyll dproducing cyanobacterium Acaryochloris marina. Proc. Natl. Acad. Sci. U.S.A. 105, 2005-2010. doi: 10.1073/pnas.0709772105

Tamagnini, P., Leitao, E., Oliveira, P., Ferreira, D., Pinto, F., Harris, D. J., et al. (2007). Cyanobacterial hydrogenases: diversity, regulation and applications. FEMS Microbiol. Rev. 31, 692-720. doi: 10.1111/j.1574-6976.2007.00085.x 
Tamura, K., Peterson, D., Peterson, N., Stecher, G., Nei, M., and Kumar, S. (2011) MEGA5: molecular evolutionary genetics analysis using maximum likelihood, evolutionary distance, and maximum parsimony methods. Mol. Biol. Evol. 28, 2731-2739. doi: 10.1093/molbev/msr121

Tel-or, E., Spath, S., Packer, L., and Mehlhorn, R. J. (1986). Carbon-13 NMR studies of salt shock-induced carbohydrate turnover in the marine cyanobacterium Agmenellum quadruplicatum. Plant Physiol. 82, 646-652. doi: 10.1104/ pp.82.3.646

Thiemermann, S., Dernedde, J., Bernhard, M., Schroeder, W., Massanz, C., and Friedrich, B. (1996). Carboxyl-terminal processing of the cytoplasmic NADreducing hydrogenase of Alcaligenes eutrophus requires the hoxW gene product. J. Bacteriol. 178, 2368-2374.

Vega-Palas, M., Flores, E., and Herrero, A. (1992). NtcA, a global nitrogen regulator from the cyanobacterium Synechococcus that belongs to the Crp family of bacterial regulators. Mol. Microbiol. 6, 1853-1859. doi: 10.1111/j.13652958.1992.tb01357.x

Volbeda, A., Charon, M.-H., Piras, C., Hatchikian, E. C., Frey, M., and FontecillaCamps, J. C. (1995). Crystal structure of the nickel-iron hydrogenase from Desulfovibrio gigas. Nature 373, 580-587. doi: 10.1038/373580a0

Volbeda, A., Martin, L., Cavazza, C., Matho, M., Faber, B. W., Roseboom, W., et al. (2005). Structural differences between the ready and unready oxidized states of [NiFe] hydrogenases. J. Biol. Inorg. Chem. 10, 239-249. doi: 10.1007/s00775005-0632-x

Warr, S. R. C., Reed, R. H., Chudek, J. A., Foster, R., and Stewart, W. D. P. (1985). Osmotic adjustment in Spirulina platensis. Planta 163, 424-429. doi: 10.1007/ BF00395153

Wilson, A., Ajlani, G., Verbavatz, J.-M., Vass, I., Kerfeld, C. A., and Kirilovsky, D. (2006). A soluble carotenoid protein involved in phycobilisome-related energy dissipation in cyanobacteria. Plant Cell 18, 992-1007. doi: 10.1105/tpc.105. 040121

Wolfe, M. T., Heo, J., Garavelli, J. S., and Ludden, P. W. (2002). Hydroxylamine reductase activity of the hybrid cluster protein from Escherichia coli. J. Bacteriol. 184, 5898-5902. doi: 10.1128/JB.184.21.5898-5902.2002
Zhang, P., Allahverdiyeva, Y., Eisenhut, M., and Aro, E. M. (2009). Flavodiiron proteins in oxygenic photosynthetic organisms: photoprotection of photosystem II by Flv2 and Flv4 in Synechocystis sp. PCC 6803. PLoS ONE 4:e5331. doi: 10.1371/ journal.pone.0005331

Zhang, S. Y., and Bryant, D. A. (2011). The Tricarboxylic acid cycle in cyanobacteria. Science 334, 1551-1553. doi: 10.1126/science. 1210858

Ziegler, K., Diener, A., Herpin, C., Richter, R., Deutzmann, R., and Lockau, W. (1998). Molecular characterization of cyanophycin synthetase, the enzyme catalyzing the biosynthesis of the cyanobacterial reserve material multiarginylpolyL-aspartate (cyanophycin). Eur. J. Biochem. 254, 154-159. doi: 10.1046/j.1432-1327.1998.2540154.x

Zimin, A., Marais, G., Puiu, D., Michael, R., Salzberg, S. L., and Yorke, J. A. (2013). The MaSuRCA genome assembler. Bioinformatics 29, 2669-2677. doi: 10.1093/ bioinformatics/btt476

Conflict of Interest Statement: The authors declare that the research was conducted in the absence of any commercial or financial relationships that could be construed as a potential conflict of interest.

Received: 22 September 2013; accepted: 15 November 2013; published online: 11 December 2013.

Citation: Kothari A, Vaughn M and Garcia-Pichel F (2013) Comparative genomic analyses of the cyanobacterium, Lyngbya aestuarii BL J, a powerful hydrogen producer. Front. Microbiol. 4:363. doi: 10.3389/fmicb.2013.00363

This article was submitted to Microbial Physiology and Metabolism, a section of the journal Frontiers in Microbiology.

Copyright (c) 2013 Kothari, Vaughn and Garcia-Pichel. This is an open-access article distributed under the terms of the Creative Commons Attribution License (CC BY). The use, distribution or reproduction in other forums is permitted, provided the original author(s) or licensor are credited and that the original publication in this journal is cited, in accordance with accepted academic practice. No use, distribution or reproduction is permitted which does not comply with these terms. 